\title{
Two Validated Spectrofluorometric Methods for Determination of Gemifloxacin Mesylate in Tablets and Human Plasma
}

\author{
Noha N. Atia, ${ }^{1}$ Ashraf M. Mahmoud, ${ }^{1,2}$ Salwa R. El-Shabouri, ${ }^{1}$ and Wesam M. El-Koussi ${ }^{1}$ \\ ${ }^{1}$ Department of Pharmaceutical Analytical Chemistry, Faculty of Pharmacy, Assiut University, Assiut 71526, Egypt \\ ${ }^{2}$ Department of Pharmaceutical Chemistry, Faculty of Pharmacy, Najran University, P.O. Box 1988, Najran 61441, Saudi Arabia
}

Correspondence should be addressed to Wesam M. El-Koussi; wesamelkosi@yahoo.com

Received 12 February 2013; Revised 16 April 2013; Accepted 16 April 2013

Academic Editor: Hian Kee Lee

Copyright ( $) 2013$ Noha N. Atia et al. This is an open access article distributed under the Creative Commons Attribution License, which permits unrestricted use, distribution, and reproduction in any medium, provided the original work is properly cited.

\begin{abstract}
Two new, sensitive, and selective spectrofluorometric methods were developed for the determination of gemifloxacin mesylate (GFX) in tablets and spiked human plasma. Method A was based on measurement of the enhanced fluorescence spectral behaviour of GFX in a sodium dodecyl sulphate (SDS) micellar system. In aqueous solution of acetate buffer pH 5.5, the fluorescence intensity of GFX was greatly enhanced about tenfold in the presence of SDS. The fluorescence intensity was measured at $402 \mathrm{~nm}$ after excitation at $274 \mathrm{~nm}$. Method B was based on Hantzsch condensation reaction between the primary amino group of GFX with acetylacetone and formaldehyde in acetate buffer of $\mathrm{pH} 3.5$ yielding a highly yellow fluorescent derivative. The reaction of GFX with acetylacetone-formaldehyde system solution resulted in bathochromic shift of both emission (476 nm) and excitation (420 nm) wavelengths. The fluorescence intensity was directly proportional to the concentration over the range $10-1000 \mathrm{ng} / \mathrm{ml}$ and $100-$ $2000 \mathrm{ng} / \mathrm{ml}$ for method A and B, respectively. The proposed methods were applied successfully for determination of GFX in its tablets and spiked plasma. Therefore, these methods can be considered of real interest for reliable and practical quality control analysis of GFX.
\end{abstract}

\section{Introduction}

Gemifloxacin mesylate (GFX) is a fluoronaphthyridone with a novel oxime functionalised pyrrolidine (Figure 1) [1]. It possesses a dual mechanism of action by inhibiting the bacterial topoisomerase IV and gyrase enzymes, resulting in interruption of bacterial DNA synthesis. Therefore, it has broad-spectrum activity against Gram-positive and Gramnegative organisms comparable to those of its quinolone counterparts which have the same pyrrolidine side chain $[1,2]$. GFX was first approved by the FDA for clinical use in 2003 for the treatment of community acquired pneumonia and acute bacterial exacerbation of chronic bronchitis [3].

Several analytical methods were reported for determination of gemifloxacin in pharmaceutical preparations or human plasma by visible spectrophotometry $[4,5]$, capillary electrophoresis [6], HPLC-MS-MS [7], HPLC [8], and
HPTLC [9]. However, these methods showed some drawbacks such as being time-consuming, tedious, or requiring expensive instruments that limit their use in quality control and routine clinical studies in developing countries where the cost is a main concern.

Spectrofluorimetric analysis constitutes a widespread, effective technique to improve analysis selectivity and sensitivity. Although, limited literatures have been reported for the determination of gemifloxacin spectrofluorometrically $[10,11]$. Micelle-enhanced spectrofluorimetric method has been reported for determination of many drugs [12-17] due to the ability of micelle formation to increase the fluorescence intensity of the weakly fluorescent compounds. Moreover, these methods introduced sensitive and nonpollutant methodology, since no organic solvents were used. Hantzsch reaction is a well-known condensation reaction that was reported as a useful pathway for determination of many drugs 


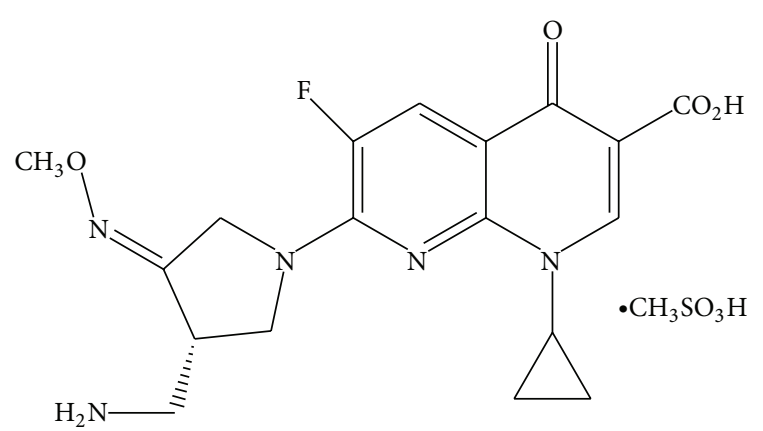

FIgURE 1: Chemical structure of gemifloxacin mesylate.

fluorometrically in biological fluids, air, or pharmaceutical preparations in trace amounts [18-22].

Therefore, the aim of this study was directed for using micelle-enhanced and Hantzsch reaction spectrofluorometric methods for developing new simple, selective, and sensitive methods for determination of GFX in its tablets and human plasma.

\section{Experimental}

2.1. Instrumentation. Spectrophotometric measurements were carried out using an LS 45 luminescence spectrometer (Perkin-Elmer, UK), equipped with a $150 \mathrm{~W}$ Xenon lamp. Slit widths for both monochromators set at $10 \mathrm{~nm}$. Data acquisition was performed by FL WinLab software, version 4.00.03 (Perkin-Elmer, UK). A $1 \mathrm{~cm}$ quartz cell was used.

A solid phase extraction (SPE) vacuum manifold with 24-position configurations (Phenomenex, USA) was used for extraction of plasma samples. Vacuum was adjusted to 5 inches for proper flow through the SPE columns. The SPE cartridge used in this study was Strata C18-U $\left(1 \mathrm{~cm}^{3} / 100 \mathrm{mg}\right.$; Phenomenex, USA).

2.2. Materials and Reagents. Gemifloxacin mesylate (99.8\%, Tabuk pharmaceutical manufacturing Co., KSA) was used as received. The commercial formulation "Factive" (Oscient Pharmaceuticals, USA) was purchased from our local market, which was labeled to contain $320 \mathrm{mg}$ of GFX per tablet. Simulated tablets were prepared in our laboratory according to similar dosage form in India "G-CIN-A" $[23,24]$ which are labeled to contain $320 \mathrm{mg}$ of GFX and $75 \mathrm{mg}$ of Ambroxol $\mathrm{HCl}$ per tablet. We used sodium dodecyl sulphate (SDS) (El-Nasr chemical Co., Egypt), cetrimide (Danochemo a subsidiary of Ferrosan, manufacturing chemists, Copenhagen, Denmark), beta-cyclodextrin ( $\beta$-CD) (Winlab Laboratory chemicals reagents fine chemicals, UK). Acetylacetone was obtained from Tedia CO., USA. 34-38\% Formaldehyde solution and other solvents and materials used throughout this study were of analytical grade. Double distilled water was obtained through WSC-4D water purification system (Hamilton Laboratory Milton Glass Ltd., Kent, USA) and used throughout the work. $0.1 \mathrm{M}$ acetate buffer solution of pH 3.5 and $50 \mathrm{mM}$ phosphate buffer $\mathrm{pH} 3$ [25] were prepared and adjusted using 3505 pH-meter (Jenway, UK). Blank human plasma samples used herein were supplied from Assiut University Hospitals (Assiut, Egypt), and they were stored in deepfreezer at $-80^{\circ} \mathrm{C}$ until analysis.

\subsubsection{Reagent Preparation}

SDS Solution. 0.1 M SDS solution was prepared by dissolving $0.29 \mathrm{~g}$ of SDS in sufficient distilled water and diluted up to $10 \mathrm{~mL}$.

Acetylacetone-Formaldehyde Solution. Into $5 \mathrm{~mL}$ calibrated flask, the reagent was freshly prepared by mixing $0.5 \mathrm{~mL}$ of $0.1 \mathrm{M}$ acetate buffer $\mathrm{pH} 3.5,0.5 \mathrm{~mL}$ acetylacetone solution, and $1 \mathrm{~mL}$ formaldehyde solution and completed to the mark with double distilled water. The flask was protected from light with aluminum foil.

\subsection{Standards and Stock Solutions}

2.3.1. Gemifloxacin Mesylate Standard Solutions. An accurately weighed amount $(25 \mathrm{mg})$ of GFX was transferred into $250 \mathrm{~mL}$ calibrated flask, dissolved in appropriate volume of double distilled water. Then, the void volume was completed with water to produce a stock solution of $100 \mu \mathrm{g} / \mathrm{mL}$. The stock solution was further diluted with water to obtain working standard solution of $5 \mu \mathrm{g} / \mathrm{mL}$.

2.3.2. Tablets Sample Solution. Twenty tablets were weighed and finely powdered. An accurately weighed quantity of the powder equivalent to $25 \mathrm{mg}$ of GFX alone or with Ambroxol in combined dosage form was transferred into a $100 \mathrm{~mL}$ calibrated flask and dissolved in about $40 \mathrm{~mL}$ of distilled water. The contents of the flask were swirled, sonicated for $5 \mathrm{~min}$, and then completed to volume with water. The contents were mixed well, filtered, and rejecting the first portion of the filtrate. The prepared solutions were diluted quantitatively with water to obtain stock solution of $5 \mu \mathrm{g} / \mathrm{mL}$ as a suitable concentration for the analysis.

\subsubsection{Plasma Sample Processing}

Sample Preparation. Plasma aliquot $(0.25 \mathrm{~mL})$ was transferred into a $2 \mathrm{~mL}$ Eppendorf tubes. Subsequently, $100 \mu \mathrm{L}$ of GFX working solutions $(2,12.5,25,50$, and $100 \mu \mathrm{g} / \mathrm{mL})$ was added in each tube. After gentle mixing, the void volume was completed to $1.5 \mathrm{~mL}$ with $50 \mathrm{mM} \mathrm{Na}_{2} \mathrm{HPO}_{4}$ (pH 3). A blank plasma sample was treated similarly.

Solid-Phase Extraction. A polymeric sorbent (Strata C18$\mathrm{U})$ was used to prepare the samples. Before extraction, the cartridges were prewashed with $2 \times 1 \mathrm{~mL}$ of methanol, followed by $2 \times 1 \mathrm{~mL}$ of distilled water. After application of the samples, the cartridges were washed with $2 \times 1 \mathrm{ml}$ portions of distilled water and $0.5 \mathrm{~mL}$ of $50 \mathrm{mM} \mathrm{Na}{ }_{2} \mathrm{HPO}_{4}(\mathrm{pH} \mathrm{3})$. Finally, GFX was eluted with $1 \mathrm{~mL}$ of methanol and $50 \mathrm{mM}$ $\mathrm{Na}_{2} \mathrm{HPO}_{4}(\mathrm{pH} \mathrm{3,} 90: 10 \mathrm{v} / \mathrm{v})$. Then $0.5 \mathrm{~mL}$ was taken from each eluent and the general procedure was followed to obtain 


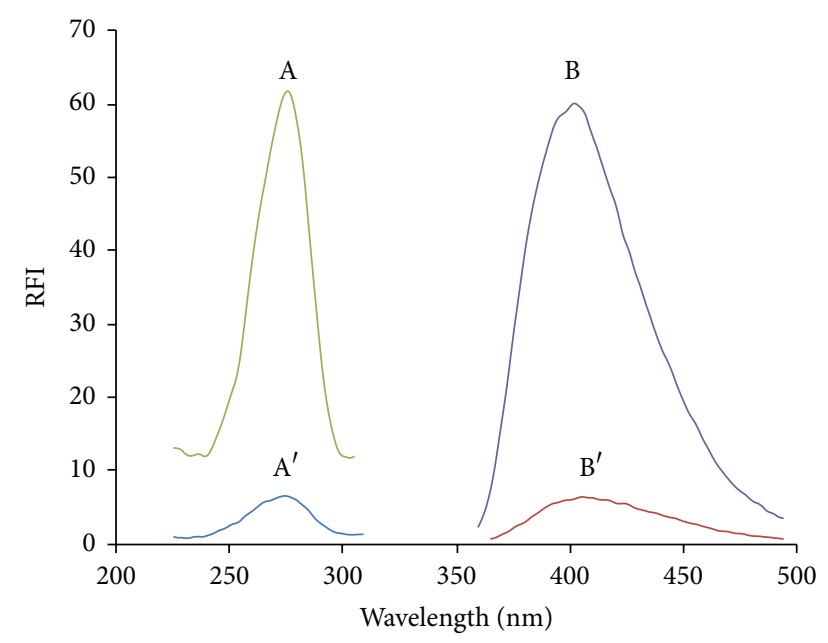

FIGURE 2: Fluorescence spectra of (A, B) GFX (500 ng/mL) in acetate buffer, pH 5.5/SDS system; ( $\left.\mathrm{A}^{\prime}, \mathrm{B}^{\prime}\right)$ GFX $(500 \mathrm{ng} / \mathrm{mL})$ in acetate buffer, $\mathrm{pH} 3.5$, where $\left(\mathrm{A}, \mathrm{A}^{\prime}\right)$ are the excitation spectra and $\left(\mathrm{B}, \mathrm{B}^{\prime}\right)$ are the emission spectra.

final concentrations of 20,125 and $500 \mathrm{ng} / \mathrm{mL}$ for method A or 250,500 and $1000 \mathrm{ng} / \mathrm{mL}$ for method B.

\subsection{General Procedures}

2.4.1. Micelle-Enhanced Spectrofluorometric Method (Method A). Aliquot of $10-1000 \mu \mathrm{L}$ of GFX standard solution $(5 \mu \mathrm{g} / \mathrm{mL})$ was transferred into a series of $5 \mathrm{~mL}$ volumetric flasks to give final concentrations of $10-1000 \mathrm{ng} / \mathrm{mL} .1 \mathrm{~mL}$ $0.2 \mathrm{M}$ acetate buffer solution, $\mathrm{pH}$ 5.5, was added to each flask, followed by $100 \mu \mathrm{L}$ of $0.1 \mathrm{M}$ SDS solution. The volume was completed with distilled water, the contents of the flasks were mixed well, and the fluorescence intensity was measured at $402 \mathrm{~nm}$ after excitation at $274 \mathrm{~nm}$, against a blank solution treated similarly.

2.4.2. Hantzsch Reaction Method (Method B). Aliquot of $0.1-2.0 \mathrm{~mL}$ of GFX standard solution $(5 \mu \mathrm{g} / \mathrm{mL})$ was mixed with $1 \mathrm{~mL}$ of acetylacetone-formaldehyde solution in a glassstoppered tube that was protected from light with aluminum foil. The mixture was heated at $100^{\circ} \mathrm{C}$ for $20 \mathrm{~min}$ in a thermostatic water bath and after that it was cooled in an ice bath. The volume was adjusted to $5 \mathrm{~mL}$ with 2-propanol to provide a final concentration ranging from $100-2000 \mathrm{ng} / \mathrm{mL}$. The fluorescence intensity was measured at $476 \mathrm{~nm}$ after excitation at $420 \mathrm{~nm}$ against a blank prepared similarly.

\section{Results and Discussion}

3.1. Spectral Characteristics. For method A, the fluorescence spectra of gemifloxacin in both aqueous and SDS systems were studied (Figure 2). GFX showed native fluorescence in aqueous solution measured at $406 \mathrm{~nm}$ after an excitation at $274 \mathrm{~nm}$. In the presence of SDS, the fluorescence intensity of GFX was enhanced nearly tenfold in comparison with its native fluorescence intensity in aqueous medium. Moreover,

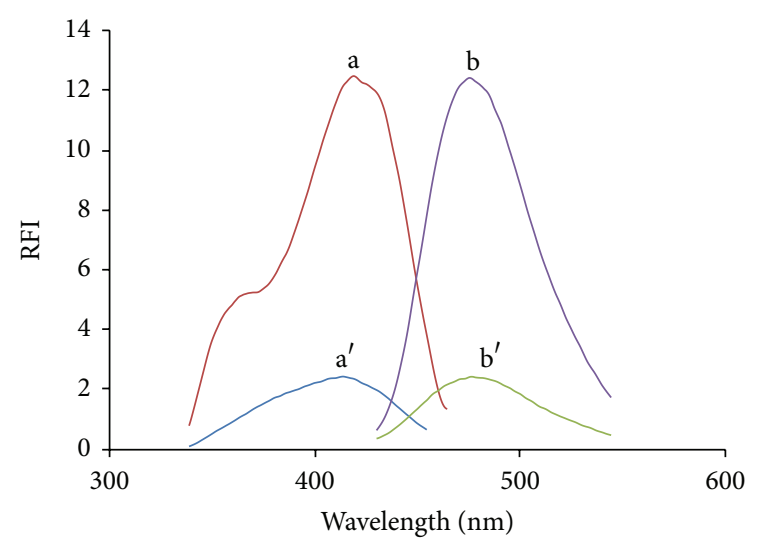

FIgURE 3: Fluorescence spectra of (a, b) gemifloxacin $(1000 \mathrm{ng} / \mathrm{mL})$ with acetylacetone-formaldehyde reagent solution, $\left(a^{\prime}, b^{\prime}\right)$ acetylacetone-formaldehyde reagent, where $\left(a, a^{\prime}\right)$ are the excitation spectra and $\left(b, b^{\prime}\right)$ are the emission spectra. $\lambda$ ex $/ \lambda \mathrm{em}=420 / 476 \mathrm{~nm}$.

the enhancement was associated with a slight blue shift ( $\lambda$ em at $402 \mathrm{~nm}$ ). It reflects that the microenvironment around GFX is quite different from that in aqueous solution. This can be attributed to restrictions imposed on the free rotational motions which are competitive with luminescent emission [26].

For method B, GFX reacts with acetylacetone and formaldehyde in an acidic-buffered medium yielding a highly yellow fluorescent product. The fluorescence intensity of the product was measured at $476 \mathrm{~nm}$ after excitation at $420 \mathrm{~nm}$ (Figure 3). The notable advantage of this reaction is the enhanced red shift in the excitation and emission wavelengths that improves the selectivity of GFX.

3.2. Optimization of Experimental Conditions. All different experimental factors influencing the development of the fluorescent product were carefully studied and optimized. Such factors were changed individually while others were kept constant. These factors were $\mathrm{pH}$, volume of the reagent, temperature and diluting solvent.

3.2.1. Micelle-Enhanced Spectrofluorometric Method. The fluorescence properties of gemifloxacin in various micellar media were studied using anionic (SDS), cationic (cetrimide) and nonionic $(\beta-C D)$ surfactants. It was observed that the fluorescence intensity of GFX showed decrease or no significant effect by using non-ionic or cationic surfactants. On the other hand, there was an obvious enhancement of the fluorescence intensity of GFX in the presence of SDS about tenfold in comparing with its aqueous solution (Figure 4(a)). Therefore, the influence of SDS on the RFI was studied using increasing volumes of $0.1 \mathrm{M}$ SDS. It was found that increasing volumes of SDS solution resulted in a corresponding increase in RFI up to $100 \mu \mathrm{L}$, after which gradual decrease in RFI was attained. Therefore, $100 \mu \mathrm{L}$ of $0.1 \mathrm{M}$ SDS solution was selected as the optimum volume (Figure 4(b)). It was noted that, the SDS aggregation equilibrium in presence of GFX in our optimal experimental conditions showed a quite different 


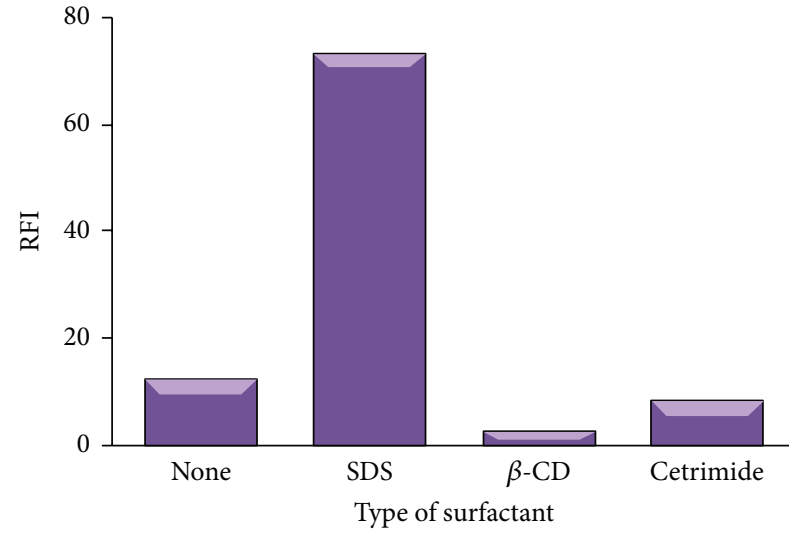

(a)

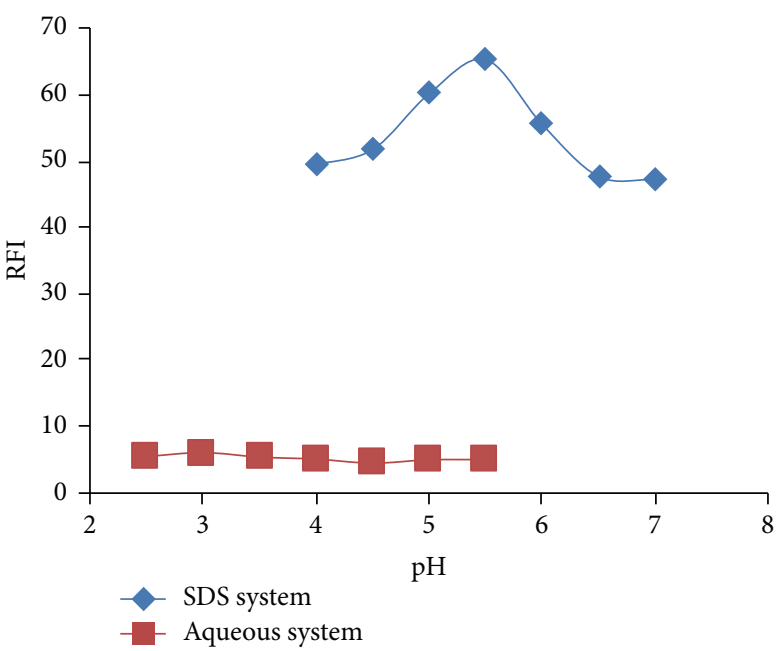

(c)

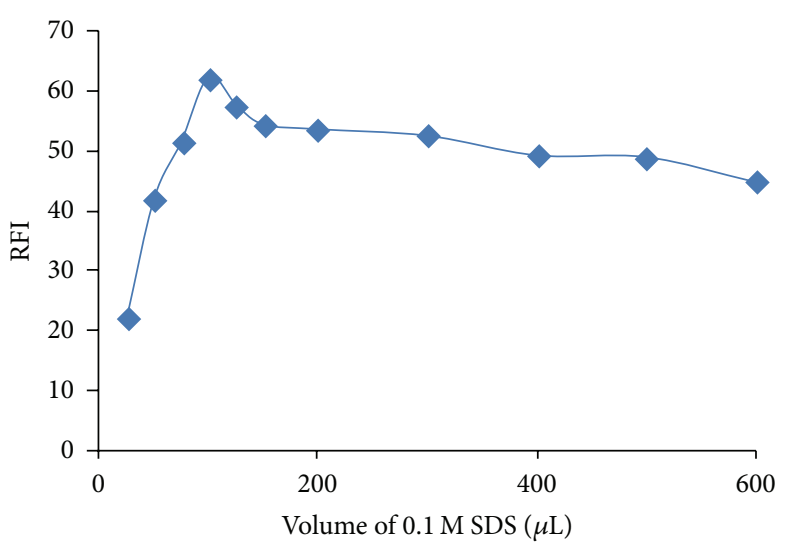

(b)

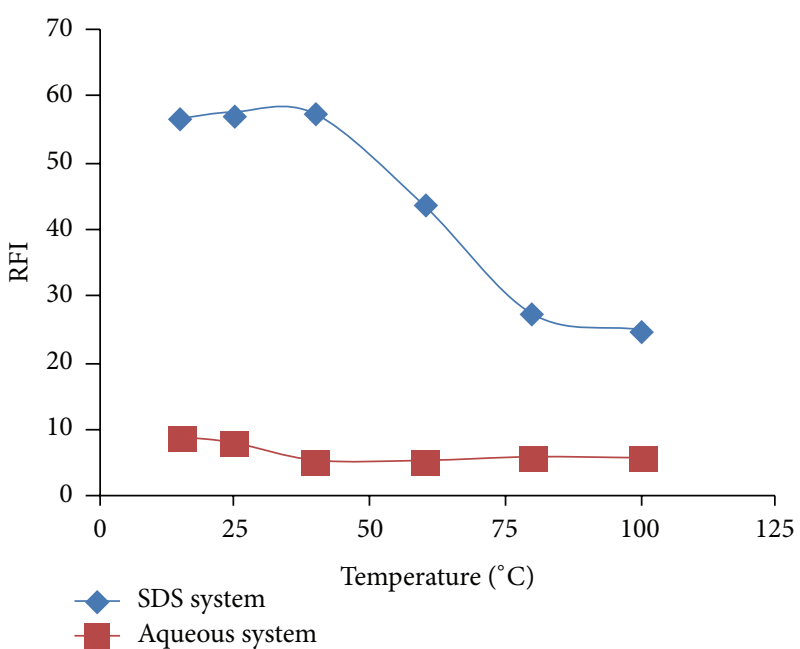

(d)

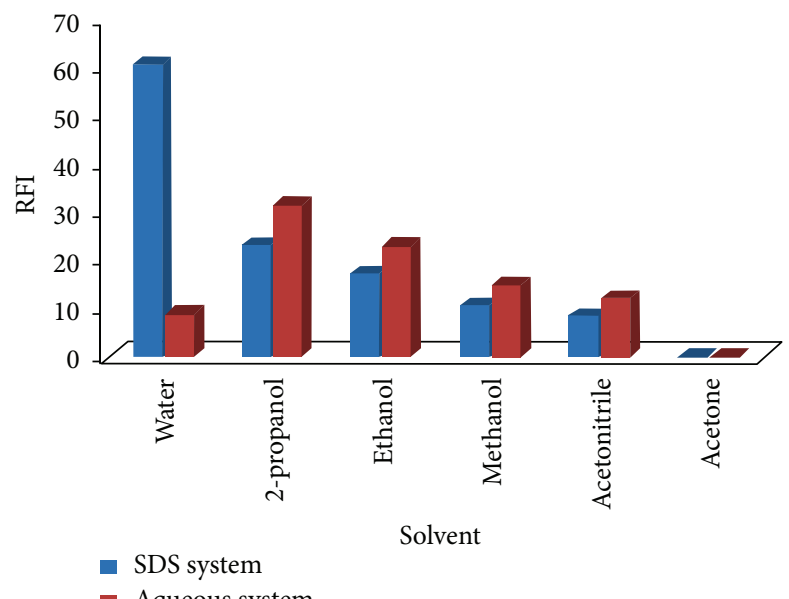

(e)

FIGURE 4: Effect of the different optimization factors. (a) Type of surfactant, (b) concentration of SDS surfactant, (c) pH, (d) temperature, and (e) diluting solvents on RFI using micelle-enhanced spectrofluorometric method. 
TABLE 1: Analytical parameters for the determination of GFX using the two proposed methods.

\begin{tabular}{lcc}
\hline Parameter & Micelle-enhanced spectrofluorometric method & Hantzsch reaction method \\
\hline Range $(\mathrm{ng} / \mathrm{mL})$ & $10-1000$ & $100-2000$ \\
Intercept $(a) \pm \mathrm{SD}^{\mathrm{a}}$ & $-0.50 \pm 0.10$ & $1.28 \pm 0.07$ \\
Slope $(b) \pm \mathrm{SD}^{\mathrm{a}}$ & $0.13 \pm 2 \times 10^{-4}$ & $0.01 \pm 4 \times 10^{-3}$ \\
Correlation coefficient $(\mathrm{r})$ & 0.9999 & 0.9988 \\
LOD $(\mathrm{ng} / \mathrm{mL})$ & 2.32 & 20.45 \\
LOQ $(\mathrm{ng} / \mathrm{mL})$ & 7.74 & 68.18 \\
\hline
\end{tabular}

${ }^{\mathrm{a}}$ Mean of six determinations.

TABLE 2: Intraday and interday precision of the proposed methods.

\begin{tabular}{|c|c|c|c|c|c|c|}
\hline \multirow{2}{*}{ Method } & \multirow{2}{*}{$\begin{array}{l}\text { Conc. } \\
\text { (ng/mL) }\end{array}$} & \multirow{2}{*}{ Recovery $(\%) \pm \mathrm{SD}^{\mathrm{a}}$} & \multicolumn{2}{|c|}{ Intraday precision } & \multicolumn{2}{|c|}{ Interday precision } \\
\hline & & & Mean $\pm S^{a}$ & $\%$ RSD & Mean $\pm S^{a}$ & \%RSD \\
\hline \multirow{3}{*}{$\begin{array}{l}\text { Micelle-enhanced } \\
\text { spectrofluorometric }\end{array}$} & 20 & $99.86 \pm 1.17$ & $100.63 \pm 1.13$ & 1.18 & $99.10 \pm 1.50$ & 1.51 \\
\hline & 125 & $96.49 \pm 0.40$ & $99.82 \pm 0.82$ & 0.82 & $99.63 \pm 1.85$ & 1.86 \\
\hline & 500 & $99.76 \pm 1.66$ & $100.34 \pm 1.09$ & 1.08 & $100.23 \pm 1.43$ & 1.42 \\
\hline \multirow{3}{*}{ Hantzsch reaction } & 250 & $99.24 \pm 2.25$ & $99.31 \pm 0.58$ & 0.58 & $98.36 \pm 1.89$ & 1.90 \\
\hline & 500 & $100.71 \pm 1.98$ & $100.56 \pm 0.70$ & 0.70 & $100.71 \pm 1.44$ & 1.43 \\
\hline & 1000 & $99.35 \pm 1.44$ & $99.86 \pm 0.44$ & 0.44 & $99.57 \pm 0.82$ & 0.82 \\
\hline
\end{tabular}

${ }^{\mathrm{a}}$ Mean of six determinations.

behavior than pure SDS aqueous solution. For GFX-SDS system, the fluorescent response showed maximum intensity at $2 \times 10^{-3} \mathrm{M}$ which is lower than the reported critical micellar concentration $(\mathrm{cmc})$ of SDS $\left(8 \times 10^{-3} \mathrm{M}\right)$ [27]. The change in the cmc of SDS in our results suggests the formation of mixed aggregates at concentrations below the reported $\mathrm{cmc}$ that was in concordance to other authors whose reported similar behavior for SDS systems [28-30].

The influence of $\mathrm{pH}$ on the micelle-enhanced fluorescence of GFX was studied carefully. The fluorescence intensity was maximal in the $\mathrm{pH}$ interval of 5.0-6.0. Thus, $\mathrm{pH} 5.5$ was selected to be the most successful for further studies (Figure 4(c)). It may be suggested that at this $\mathrm{pH}$ value (5.5) GFX is present in its protonated form, because the fluorescence intensity of protonated species is always higher than that of neutral species $[31,32]$. This can be inferred that protonated forms interact more strongly with the anionic micelles of SDS than the neutral forms of the drugs. Different buffer solutions (acetate, phosphate, and Torell and Stenhagen) were tested. The results revealed that the acetate buffer solution of $\mathrm{pH} 5.5$ achieved the maximum fluorescence intensity, and the variation in the buffer concentration did not show any significant change in the fluorescence intensity. A $0.2 \mathrm{M}$ acetate buffer was selected to obtain an adequate buffering capacity for further measurements.

The ionic strength can also influence significantly the solubilization of a drug in micellar solutions, especially in case of ionic surfactants [33]. Therefore, the effect of the addition of inert salt such as $\mathrm{KCl}$ on micellar solutions of GFX was tested. It was found that an increase of concentration above $5 \times 10^{-2} \mathrm{M}$ provoked a clouding phenomenon to the system, and below this value, no significant effect was observed.

Another factor that affects the fluorescence intensity of the micellar system of GFX is the temperature. The effect of temperature was studied in the range $25-100^{\circ} \mathrm{C}$ in a thermostatically controlled water bath. It was found that increasing the temperature resulted in a decrease in the RFI (Figure 4(d)). This effect can be explained by higher internal conversion as the temperature increases, facilitating nonradiative deactivation of the excited singlet state [34]. The results indicated that the fluorescence intensity was immediately developed at room temperature and remained stable for at least $2 \mathrm{hr}$.

Finally, the influence of different diluting solvents (water, methanol, ethanol, isopropanol, acetonitrile, or acetone) on the fluorescence intensity of GFX-SDS system was also investigated (Figure 4(e)). The results revealed that water was the best solvent for dilution in presence of SDS, as it gave the highest RFI and the lowest blank reading, while distinct and sharp decrease in the relative fluorescence intensities was observed in the SDS system using other solvents. This effect is attributed to their denaturating effect on the micelles, where short-chain alcohols (methanol, ethanol, and propanol) are solubilized mainly in the aqueous phase and affect the micellization process by modifying the solvent properties. Addition of these alcohols also results in a reduction of the size of the micelles but with a progressive breakdown of the surfactant aggregate at very high concentration [35].

3.2.2. Hantzsch Reaction Method. Effect of reagents composition; the effect of acetylacetone and formaldehyde reagents 
TABLE 3: Robustness of the proposed methods.

\begin{tabular}{|c|c|c|}
\hline Method & $\begin{array}{l}\text { Experimental } \\
\text { parameter } \\
\text { variation }\end{array}$ & Recovery $(\%) \pm S^{a}$ \\
\hline & No variation $^{\mathrm{b}}$ & $101.07 \pm 0.34$ \\
\hline & SDS volume $(\mu \mathrm{L})$ & \\
\hline & 90 & $96.10 \pm 1.13$ \\
\hline & 110 & $99.16 \pm 0.44$ \\
\hline & $\mathrm{pH}$ & \\
\hline \multirow{12}{*}{$\begin{array}{l}\text { Micelle-enhanced } \\
\text { spectrofluorometric }\end{array}$} & 5.3 & $101.23 \pm 1.27$ \\
\hline & 5.7 & $98.52 \pm 0.55$ \\
\hline & Temperature $\left({ }^{\circ} \mathrm{C}\right)$ & \\
\hline & 20 & $102.13 \pm 0.91$ \\
\hline & 30 & $100.81 \pm 1.92$ \\
\hline & No variation $^{\mathrm{b}}$ & $101.57 \pm 0.53$ \\
\hline & $\mathrm{pH}$ & \\
\hline & 3.3 & $100.05 \pm 1.83$ \\
\hline & 3.7 & $101.02 \pm 2.79$ \\
\hline & $\begin{array}{l}\text { Acetylacetone } \\
\text { volume }(\mathrm{mL})\end{array}$ & \\
\hline & 0.4 & $99.16 \pm 1.40$ \\
\hline & 0.6 & $99.86 \pm 0.91$ \\
\hline \multirow[t]{9}{*}{ Hantzsch reaction } & $\begin{array}{l}\text { Formaldehyde } \\
\text { volume }(\mathrm{mL})\end{array}$ & \\
\hline & 0.8 & $97.60 \pm 0.92$ \\
\hline & 1.2 & $100.90 \pm 2.30$ \\
\hline & Temperature $\left({ }^{\circ} \mathrm{C}\right)$ & \\
\hline & 95 & $97.06 \pm 1.40$ \\
\hline & 105 & $102.36 \pm 1.90$ \\
\hline & Heating time (min) & \\
\hline & 18 & $99.31 \pm 2.74$ \\
\hline & 22 & $102.33 \pm 1.83$ \\
\hline
\end{tabular}

${ }^{\mathrm{a}}$ Mean of three determinations.

${ }^{\mathrm{b}}$ Following the general assay procedure conditions.

volume in the final reagent solution were studied individually to show their influence on RFI (Figure 5). Different volumes ranging from 0.1 to $1.5 \mathrm{~mL}$ of either acetylacetone or formaldehyde solution (34-38\%) were tested. A reagent composed of both $0.5 \mathrm{~mL}$ of acetylacetone and $1 \mathrm{~mL}$ of formaldehyde resulted in the maximum RFI and it was selected for further studies (Figures 5(a) and 5(b)).

In order to select the most appropriate $\mathrm{pH}$, the reaction was carried out at different $\mathrm{pHs}$. First, the $\mathrm{pH}$ of the reaction medium was changed over $\mathrm{pH}$ range 3-6 using $0.1 \mathrm{M}$ acetate buffer to obtain the highest RFI of the resulted product. The maximum RFI was obtained at $\mathrm{pH} 3.5$ (Figure 5(c)). Then, a series of different buffer systems (acetate, Mcllvaine, and Torell and Stenhagen buffers) of $\mathrm{pH} 3.5$ was studied; the results indicated that acetate buffer was still the superior one. Also different volumes of the optimum buffer solution ranging from 0.1 to $2 \mathrm{~mL}$ were tested to obtain the maximum sensitivity. $0.5 \mathrm{~mL}$ of acetate buffer was selected for further investigations (Figure 5(d)).

After individual optimization of the reagent components, the effect of the final volume of the reagent system solution was studied over the range $0.1-1.5 \mathrm{~mL}$. It was found that $1 \mathrm{~mL}$ of the reagent system was the optimum volume for further studies (Figure 5(e)).

The optimum temperature for the reaction was determined by investigating the RFI at different temperatures in the range $25-110^{\circ} \mathrm{C}$ in a thermostatically controlled water bath. The results revealed that the heating step is essential. The maximum RFI was reached after $20 \mathrm{~min}$ at $100^{\circ} \mathrm{C}$ (Figure 5(f)). Moreover, to select the most appropriate diluting solvent, the reaction mixture was diluted using different solvents (water, methanol, ethanol, 2-propanol, acetonitrile, or acetone). The results showed that 2-propanol was the best solvent for dilution as it achieves the highest RFI.

3.3. Method Validation. The method was validated according to ICH guidelines of the validation of analytical methods [36]. All results were expressed as percentages, with $n$ representing the number of values. Microsoft office excel 2007 was used for statistical analysis. A 5\% significance level was used for evaluation.

3.3.1. Linearity, Limits of Detection, and Quantitation. Under the optimum conditions, linear plots with good correlation coefficients $(0.9999$ and 0.9988$)$ were obtained in the concentration ranges of $10-1000$ and $100-2000 \mathrm{ng} / \mathrm{mL}$ for micelle-enhanced fluorescence and Hantzsch reaction methods, respectively. The limits of detection (LOD) and quantitation (LOQ) were determined using the formula: $\mathrm{LOD}$ or LOQ $=\kappa \mathrm{SD}_{a} / b$, where $\kappa=3.3$ for LOD and 10 for $\mathrm{LOQ}, \mathrm{SD}_{a}$ is the standard deviation of the intercept, and $b$ is the slope. The LOD values were 2.32 and $20.45 \mathrm{ng} / \mathrm{mL}$ for micelle-enhanced fluorescence and Hantzsch reaction methods, respectively. The parameters for the analytical performance of the proposed method are summarized in Table 1.

3.3.2. Precision and Accuracy. The precision of the proposed methods was determined by replicate analysis of six separate sample solutions at three concentration levels of GFX. The relative standard deviations (RSD) were $0.82-1.86$ and $0.44-1.90 \%$ for micelle-enhanced fluorescence and Hantzsch reaction methods, respectively. Table 2 indicates the good reproducibility of the proposed methods. The accuracy of both methods was determined by investigating the recovery of GFX at three concentrations levels covering the specified range (six replicates of each concentration). The results shown in Table 2 depict good accuracy for the proposed methods.

3.3.3. Robustness. It was estimated by testing the susceptibility of measurements to deliberate variation of the analytical conditions. It was found that minor changes that may take place during the experimental operation did not affect the 


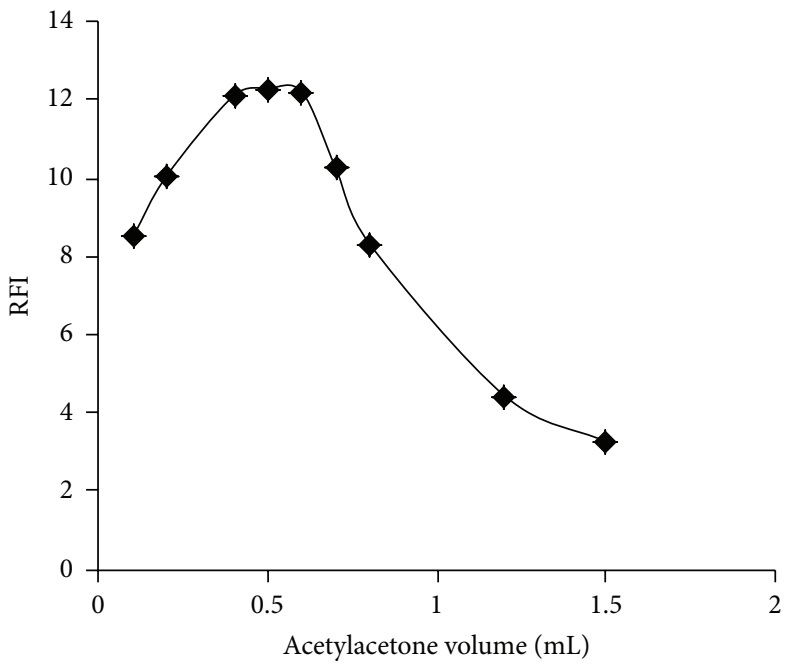

(a)

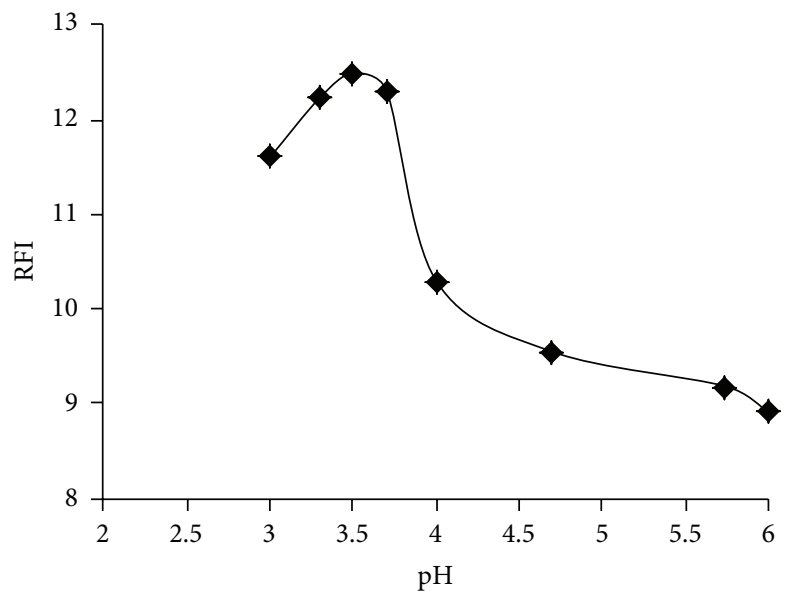

(c)

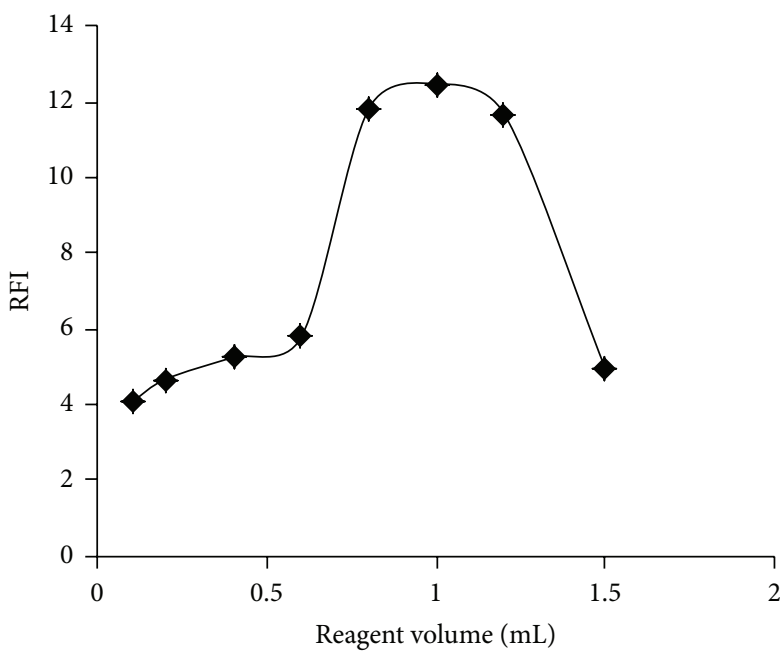

(e)

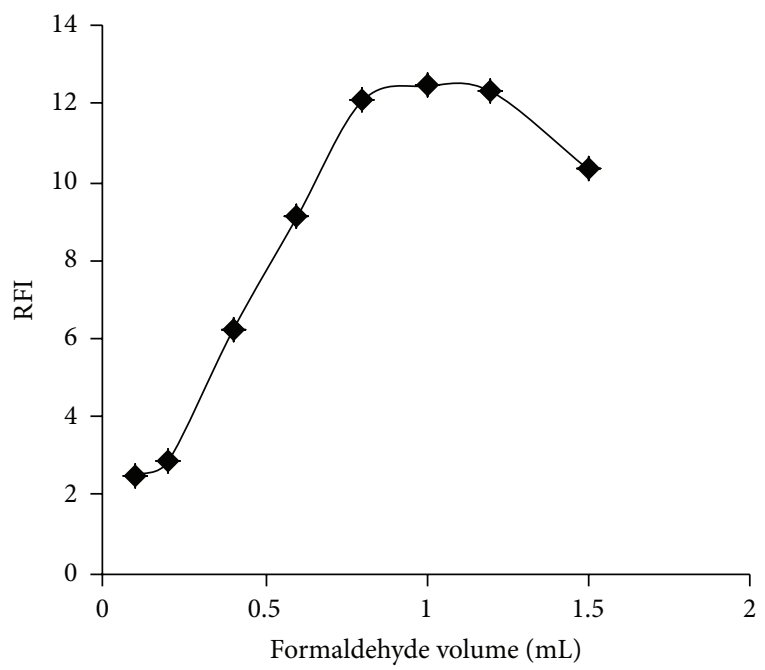

(b)

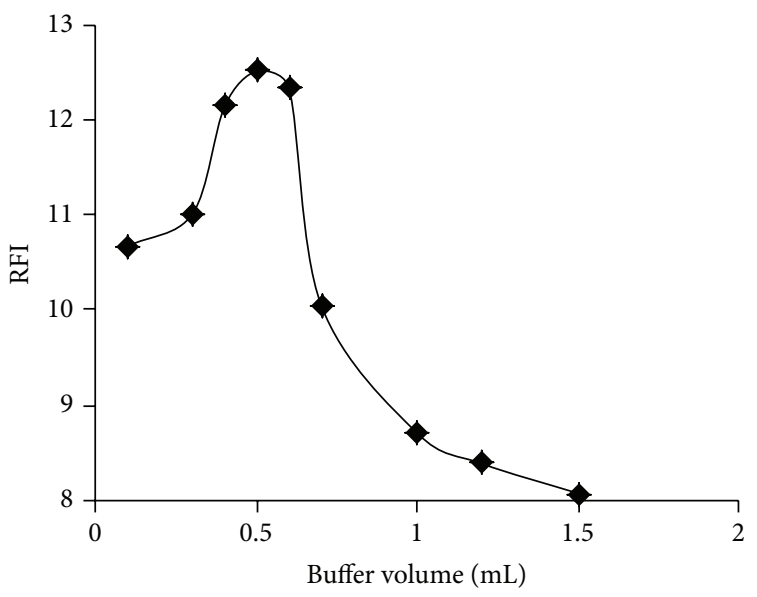

(d)

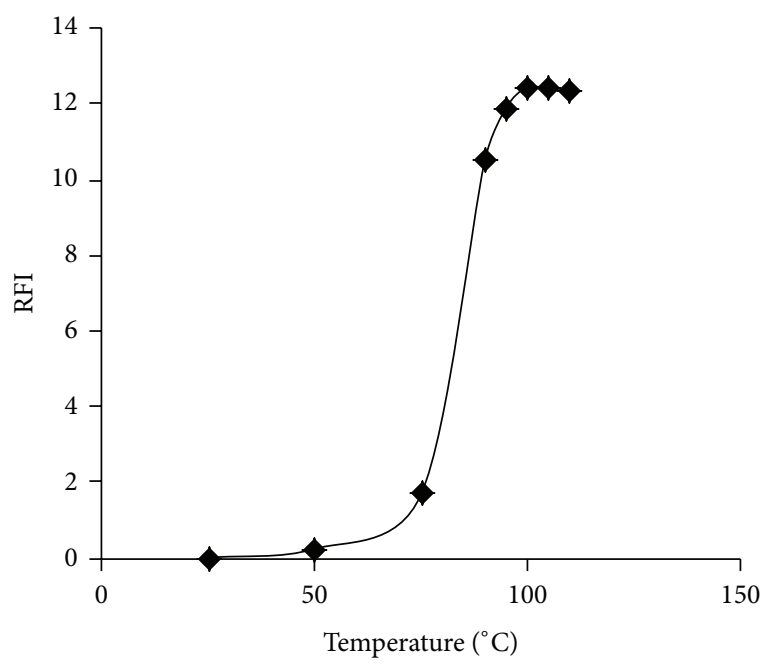

(f)

FIGURE 5: Effect of the different optimization factors. (a) Volume of acetylacetone, (b) volume of formaldehyde, (c) pH, (d) volume of buffer, (e) volume of reagent components, and (f) temperature on RFI using Hantzsch reaction. 
TABLE 4: Determination of GFX in its pharmaceutical dosage forms using the proposed methods.

\begin{tabular}{lccc}
\hline \multirow{2}{*}{ Dosage form } & \multicolumn{3}{c}{ Recovery \% SD $(n=4)$} \\
& Micelle-enhanced spectrofluorometric method & Hantzsch reaction method & Reported method $^{\text {a }}$ \\
\hline & $99.78 \pm 0.88$ & $99.44 \pm 0.81$ & $100.09 \pm 0.50$ \\
Factive & $t=0.61^{\mathrm{b}}$ & $t=1.35^{\mathrm{b}}$ & \\
& $F=3.17^{\mathrm{b}}$ & $2.69^{\mathrm{b}}$ & $100.85 \pm 0.56 \quad t=1.19^{\mathrm{b}}$ \\
\hline & $99.07 \pm 0.66$ & $F=3.49^{\mathrm{b}}$ \\
\hline
\end{tabular}

${ }^{\mathrm{a}}$ Reference [9].

${ }^{\mathrm{b}}$ Theoretical value for $t$ and $F$ at $95 \%$ confidence limit, $t=2.45$ and $F=9.23$.

TABLE 5: Determination of GFX in spiked human plasma samples using the proposed methods.

\begin{tabular}{lccc}
\hline Method & Spiked amount $(\mathrm{ng} / \mathrm{mL})$ & Found $(\mathrm{ng} / \mathrm{mL})$ & ${\text { Recovery } \% \pm \mathrm{SD}^{\mathrm{a}}}$ \\
\hline & 20 & 19.52 & $97.60 \pm 0.92$ \\
Micelle-enhanced spectrofluorometric & 125 & 123.98 & $99.18 \pm 1.23$ \\
& 500 & 495.50 & $99.10 \pm 0.69$ \\
Hantzsch reaction & 250 & 248.11 & $99.25 \pm 0.97$ \\
& 500 & 498.25 & $99.65 \pm 1.42$ \\
\end{tabular}

${ }^{\mathrm{a}}$ Mean of five determinations.

RFI of both methods. The results for the proposed methods are summarized in Table 3.

3.3.4. Specificity. The specificity of the proposed methods was investigated by considering the interference liabilities from Ambroxol $\mathrm{HCl}$ in the combined dosage form. Results present in Table 4 indicate that no interference from Ambroxol $\mathrm{HCl}$ was observed.

\subsection{Applications of the Proposed Methods}

3.4.1. Determination of GFX in Dosage Forms. The applicability of the proposed methods was tested by the determination of GFX in its marketed product (Factive Tablet) and simulated tablet with ambroxol $\mathrm{HCl}$ as a combined dosage form. The results obtained are accurate and precise as indicated by the excellent percentage recovery (Table 4).

Statistical analysis of the results obtained by the proposed methods and those given by reference method [9] was performed using the Student's $t$-test and the variance ratio $F$ test. The calculated values did not exceed the theoretical ones, indicating no significant difference between the compared methods regarding accuracy and precision, respectively. The recovery results of simulated tablets also indicated the selectivity of the proposed methods for GFX in presence of Ambroxol HCl (Table 4). Therefore, the proposed methods are recommended for the quality control analysis of GFX in its pharmaceutical preparations.

3.4.2. Determination of GFX in Plasma. The high sensitivity of the proposed methods allowed the determination of GFX in spiked human plasma. Allen et al. [37] studied the pharmacokinetic parameters of GFX in healthy volunteers after a single oral dose administration. This method indicated that the maximum concentration $\left(C_{\max }\right)$ of the drug was achieved approximately one hour after dosing, and the mean $C_{\max }$ value was found as $1.48 \pm 0.39 \mu \mathrm{g} / \mathrm{mL}$ following a single oral dose of $320 \mathrm{mg}$ GFX. Therefore, the drug level in plasma is within the working linearity range of the proposed method (Table 1).

Recently, solid phase extraction (SPE) becomes the most commonly used technique for sample extraction (especially of biological origins) due to its environmental safety. Compared to liquid-liquid extraction [11], the SPE method has several advantages such as making complete phase separations, high quantitative recoveries, no need for using expensive breakable specialty glassware, and disposal of large quantities of organic solvents. Hence, SPE represents efficient separation of interfering substances from analytes without tedious and time-consuming steps. Therefore, a polymeric SPE cartridge was used to prepare the samples in this study.

Hobara et al. introduced simple SPE method for determination of fleroxacin in rat plasma [38]. This method was used with slight modification to be more compatible with our method. This modification includes increasing the volume of spiked plasma to ensure the efficiency of this method (as the reported method was proposed for real plasma samples). This simple and efficient extraction procedure introduces successful method for GFX analysis in human plasma. Table 5 indicates that the obtained results are satisfactorily accurate and precise.

\section{Suggested Mechanism of the Proposed Methods}

4.1. Micelle-Enhanced Spectrofluorometric Method. This method has been reported for determination of many 
<smiles>C/C=N/OC1CN(c2nc3c(cc2F)c(=O)c(C(=O)[O-])cn3C2CC2)C[C@@H]1CN[18OH]</smiles>

Protolytic equilibrium of GFX<smiles>CCCCCCCCCCCCOS(=O)(=O)O[Na]</smiles>

SDS<smiles>[R][CH]C1CC1n1cc(C(=O)O)c(=O)c2cc(F)c(N3CC(=NO)[C@@H](CN)C3)nc21</smiles>

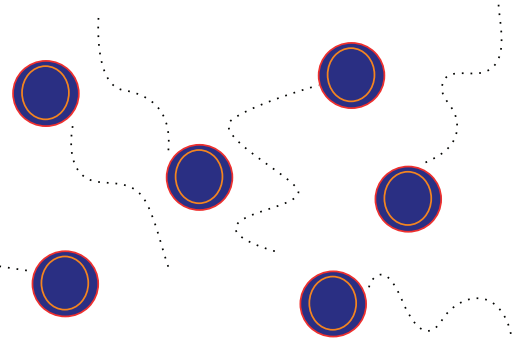

SDS monomers

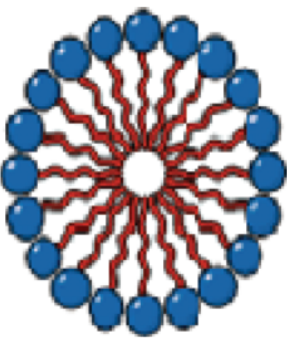

GFX-SDS system

SCHEME 1: The suggested mechanism for GFX-SDS micelle formation.<smiles>CC(=O)/C=C/C=O</smiles><smiles>CO/N=C1\CN(c2nc3c(cc2F)c(=O)c(C(=O)O)cn3C2CC2)C[C@@H]1CN</smiles><smiles>CO/N=C1\CN(c2nc3c(cc2F)c(=O)c(C(=O)O)cn3C2CC2)C[C@@H]1CN1C(C)=C(C(C)=O)CC(C(C)=O)=C1C</smiles>

SCHEME 2: The suggested mechanism for the Hantzsch reaction between gemifloxacin and acetylacetone-formaldehyde reagent. 
fluoroquinolones [12-15] and other compounds [16, 17] using different types of surfactants. In the presence of SDS anionic micelles, gemifloxacin is solubilized in a more favourable microenvironment that produces an important improvement in fluorescence intensity. GFX possesses two ionizable functional groups: a carboxylic group $\left(\mathrm{pKa}_{1}-6.5\right)$ and a basic amino group $\left(\mathrm{pKa}_{2}-8.9\right)$. It is thought that in the micellar phase, SDS could form an ion paired species with GFX through the interaction between the SDS negative sulphonyl $\left(\mathrm{OSO}_{3}^{-}\right)$group and the protonated basic amino group of GFX (Scheme 1).

4.2. Hantzsch Reaction Mechanism. Hantzsch reaction occurs between acetylacetone ( $\beta$-diketone derivative) in combination with formaldehyde and the aliphatic amino group containing compounds [18-22]. GFX reacts via its primary aliphatic amino group toward this combination in an acidicbuffered medium yielding a highly yellow fluorescent condensation product (Scheme 2).

\section{Conclusion}

The proposed methods are quite simple, accurate, precise, and do not require tedious extraction procedure. Considering the limits of detection and/or concentrations ranges, the developed methods are highly sensitive. Moreover, the micelleenhanced spectrofluorometric method has additional advantages that it is rapid and nonpollutant (organic solvents free) that can be used as an alternative to the more timeconsuming, expensive HPLC methods. The proposed methods were successfully applied for determining GFX in its tablets or plasma samples without any interference from the matrices. Thus, it can be effectively used for routine analysis of GFX in pharmaceutical industries, hospitals, and research laboratories.

\section{Conflict of Interests}

All authors declare that there is no conflict of interests in their submitted paper.

\section{References}

[1] J. I. Oh, K. S. Paek, M. J. Ahn et al., "In vitro and in vivo evaluations of LB20304, a new fluoronaphthyridone," Antimicrobial Agents and Chemotherapy, vol. 40, no. 6, pp. 1564-1568, 1996.

[2] A. Schulte and P. Heisig, "In vitro activity of gemifloxacin and five other fluoroquinolones against defined isogenic mutants of Escherichia coli, Pseudomonas aeruginosa and Staphylococcus aureus," Journal of Antimicrobial Chemotherapy, vol. 46, no. 6, pp. 1037-1038, 2000.

[3] L. D. Saravolatz and J. Leggett, "Gatifloxacin, gemifloxacin, and moxifloxacin: the role of 3 newer fluoroquinolones," Clinical Infectious Diseases, vol. 37, no. 9, pp. 1210-1215, 2003.

[4] M. V. Krishna and D. G. Sankar, "Utility of $\sigma$ and $\pi$-acceptors for the spectrophotometric determination of gemifloxacin mesylate in pharmaceutical formulations," E-Journal of Chemistry, vol. 5, no. 3, pp. 493-498, 2008.
[5] M. V. Krishna and D. G. Sankar, "Spectrophotometric determination of gemifloxacin mesylate in pharmaceutical formulations through ion-pair complex formation," E-Journal of Chemistry, vol. 5, no. 3, pp. 515-520, 2008.

[6] A. A. Elbashir, B. Saad, A. S. M. Ali, K. M. M. Al-Azzam, and H. Y. Aboul-Enein, "Validated stability indicating assay of gemifloxacin and lomefloxacin in tablet formulations by capillary electrophoresis," Journal of Liquid Chromatography and Related Technologies, vol. 31, no. 10, pp. 1465-1477, 2008.

[7] E. Doyle, S. E. Fowles, D. F. McDonnell, R. McCarthy, and S. A. White, "Rapid determination of gemifloxacin in human plasma by high-performance liquid chromatography-tandem mass spectrometry," Journal of Chromatography B, vol. 746, no. 2, pp. 191-198, 2000.

[8] B. M. H. Al-Hadiya, A. A. Khady, and G. A. E. Mostafa, "Validated liquid chromatographic-fluorescence method for the quantitation of gemifloxacin in human plasma," Talanta, vol. 83, no. 1, pp. 110-116, 2010.

[9] A. R. Rote and S. P. Pingle, "Reverse phase-HPLC and HPTLC methods for determination of gemifloxacin mesylate in human plasma," Journal of Chromatography B, vol. 877, no. 29, pp. 37193723, 2009.

[10] N. F. Youssef and L. I. Bebawy, "Spectrofluorimetric methods for the determination of gemifloxacin mesylate and cefamandole nafate in bulk powder and pharmaceutical preparations," Bulletin of the Faculty of Pharmacy, vol. 44, no. 3, pp. 215-227, 2006.

[11] S. K. Tekkeli and A. Önal, "Spectrofluorimetric methods for the determination of gemifloxacin in tablets and spiked plasma samples," Journal of Fluorescence, vol. 21, no. 3, pp. 1001-1007, 2011.

[12] M. Rizk, F. Belal, F. Ibrahim, S. Ahmed, and N. El-Enany, "Spectrofluorimetric analysis of certain 4-quinolone in pharmaceuticals and biological fluids," Pharmaceutica Acta Helvetiae, vol. 74, no. 4, pp. 371-377, 2000.

[13] J. L. Vílchez, J. Taoufiki, O. Ballesteros, and A. Navalón, "Micelle-enhanced spectrofluorimetric method for the determination of antibacterial trovafloxacin in human urine and serum," Microchimica Acta, vol. 150, no. 3-4, pp. 247-252, 2005.

[14] J. A. Ocaña, F. J. Barragán, and M. Callejón, “Spectrofluorimetric and micelle-enhanced spectrofluorimetric determination of gatifloxacin in human urine and serum," Journal of Pharmaceutical and Biomedical Analysis, vol. 37, no. 2, pp. 327-332, 2005.

[15] J. A. O. González, M. Callejón Mochón, and F. J. B. De La Rosa, "Spectrofluorimetric determination of levofloxacin in tablets, human urine and serum," Talanta, vol. 52, no. 6, pp. 1149-1156, 2000.

[16] Q. Wang, Z. Liu, H. Yuan, and R. Cai, "Micelle enhanced catalytic-fluorimetric determination of hemoglobin," Chinese Journal of Analytical Chemistry, vol. 29, no. 4, pp. 423-424, 2001.

[17] J. L. Manzoori and M. Amjadi, "Spectrofluorimetric and micelle-enhanced spectrofluorimetric methods for the determination of gemfibrozil in pharmaceutical preparations," Journal of Pharmaceutical and Biomedical Analysis, vol. 31, no. 3, pp. 507-513, 2003.

[18] J. Al-Zehouri, S. Al-Madi, and F. Belal, "Determination of the antiepileptics vigabatrin and gabapentin in dosage forms and biological fluids using Hantzsch reaction," ArzneimittelForschung, vol. 51, no. 2, pp. 97-103, 2001.

[19] S. M. Sabry, M. Abdel-Hady, M. Elsayed, O. T. Fahmy, and H. M. Maher, "Study of stability of methotrexate in acidic solution 
Spectrofluorimetric determination of methotrexate in pharmaceutical preparations through acid-catalyzed degradation reaction," Journal of Pharmaceutical and Biomedical Analysis, vol. 32, no. 3, pp. 409-423, 2003.

[20] C. Lee, X. Qiao, D. E. Goeger, and K. E. Anderson, "Fluorometric measurement of 5-aminolevulinic acid in serum," Clinica Chimica Acta, vol. 347, no. 1-2, pp. 183-188, 2004.

[21] Q. Peng and C. Jiang, "A new spectrofluorimetric method for determination of trace amounts 5-hydroxytryptamine in human urine and serum," Journal of Fluorescence, vol. 17, no. 3, pp. 339-343, 2007.

[22] Q. Peng, J. He, and C. Jiang, "A new spectrofluorimetric method for determination of trace amounts histamine in human urine and serum," Luminescence, vol. 24, no. 3, pp. 135-139, 2009.

[23] S. B. Wankhede, A. M. Mahajan, and S. S. Chitlange, "Simultaneous spectrophotometric estimation of gemifloxacin mesylate and ambroxol hydrochloride in tablets," Der Pharma Chemica, vol. 3, no. 1, pp. 269-273, 2011.

[24] D. Nagavalli, G. Abirami, and S. K. Kumar, "Validated HPLC method for the simultaneous estimation of gemifloxacin mesylate and ambroxol hydrochloride in bulk and tablet dosage form," Journal of Pharmacy Research, vol. 4, no. 6, pp. 1701-1703, 2011.

[25] A. I. Vogel, G. H. Jeffery, and A. Israel, Vogel's Textbook of Quantitative Chemical Analysis, 1989.

[26] C. C. Wang, A. N. Masi, and L. Fernández, "On-line micellarenhanced spectrofluorimetric determination of rhodamine dye in cosmetics," Talanta, vol. 75, no. 1, pp. 135-140, 2008.

[27] E. Pramauro and E. Pelezetti, Surfactants in Analytical Chemistry: Applications of Organized Amphiphilic Media, 1996.

[28] P. Paton-Morales and F. I. Talens-Alesson, "Effect of ionic strength and competitive adsorption of $\mathrm{Na}^{+}$on the flocculation of lauryl sulfate micelles with $\mathrm{Al}^{3+}$," Langmuir, vol. 17, no. 20, pp. 6059-6064, 2001.

[29] A. J. M. Valente, H. D. Burrows, R. F. Pereira, A. C. F. Ribeiro, J. L. G. C. Pereira, and V. M. M. Lobo, "Effect of europium(III) chloride on the aggregation behavior of sodium dodecyl sulfate," Langmuir, vol. 22, no. 13, pp. 5625-5629, 2006.

[30] A. C. S. Neves, A. J. M. Valente, H. D. Burrows, A. C. F. Ribeiro, and V. M. M. Lobo, "Effect of terbium(III) chloride on the micellization properties of sodium decyl- and dodecyl-sulfate solutions," Journal of Colloid and Interface Science, vol. 306, no. 1, pp. 166-174, 2007.

[31] L. Ohannesian and A. Streeter, Handbook of Pharmaceutical Analysis, New York, NY, USA, 2001.

[32] L. Ohannesian and A. J. Streeter, Handbook of Pharmaceutical Analysis, Edited by M. Dekker, 2002.

[33] M. J. Rosen, Surfactants and Interfacial Phenomena, New York, NY, USA, 1989

[34] D. A. Skoog, D. M. west, F. J. Holler, and S. R. Crouch, Fundamentals of Analytical Chemistry, Brooks Cole, Belmont, Calif, USA, 2004.

[35] R. Leung and D. O. Shah, "Dynamic properties of micellar solutions. I. Effects of short-chain alcohols and polymers on micellar stability," Journal of Colloid And Interface Science, vol. 113, no. 2, pp. 484-499, 1986.

[36] I. C. H. Guideline, Q2(R1) Validation of Analytical Procedures: Text and Methodology, 2005.

[37] A. Allen, E. Bygate, S. Oliver et al., "Pharmacokinetics and tolerability of gemifloxacin (SB-265805) after administration of single oral doses to healthy volunteers," Antimicrobial Agents and Chemotherapy, vol. 44, no. 6, pp. 1604-1608, 2000.
[38] N. Hobara, H. Kameya, N. Hokama, S. Ohshiro, and M. Sakanashi, "Rapid and simple determination of fleroxacin in rat plasma using a solid-phase extraction column," Journal of Chromatography B, vol. 703, no. 1-2, pp. 279-283, 1997. 

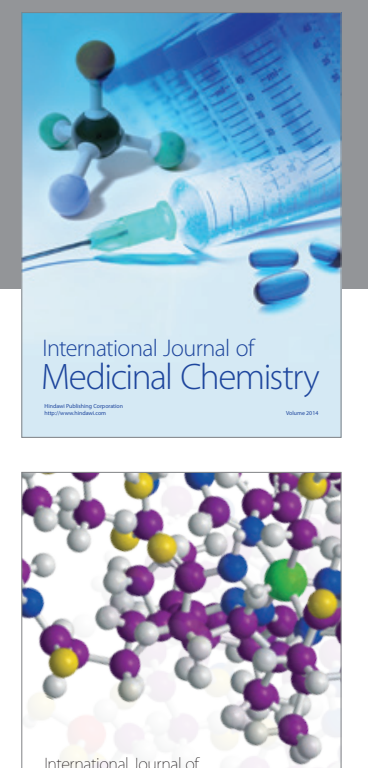

\section{Carbohydrate} Chemistry

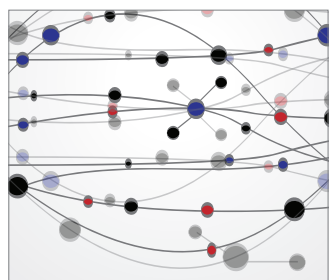

The Scientific World Journal
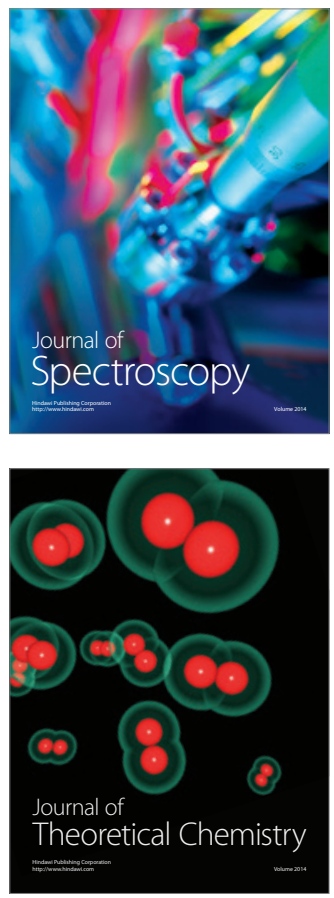
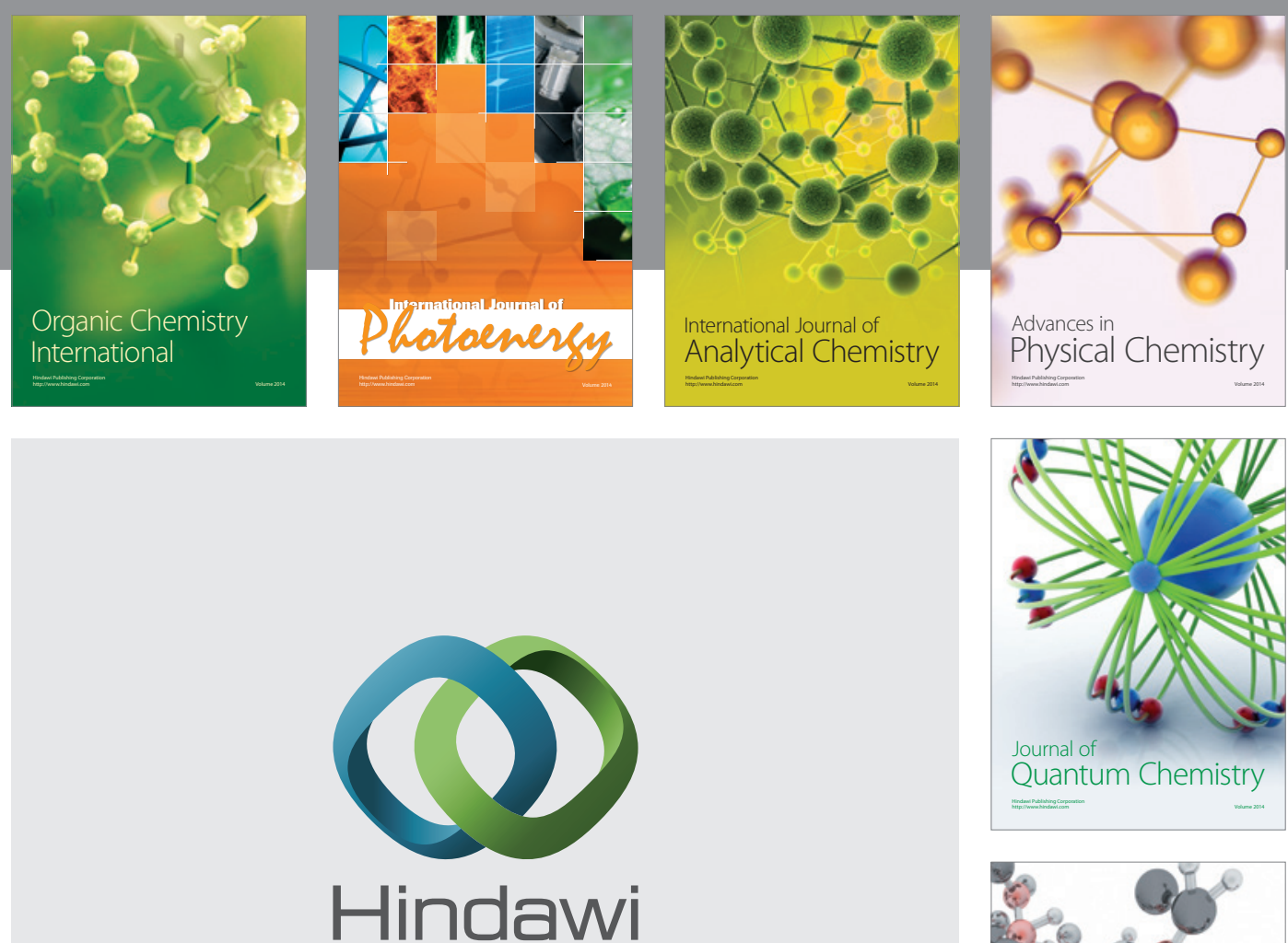

Submit your manuscripts at

http://www.hindawi.com

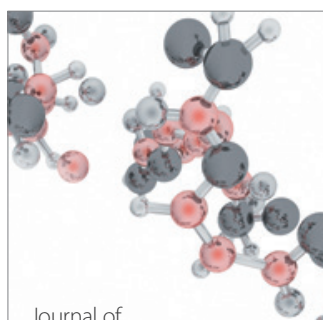

Analytical Methods

in Chemistry

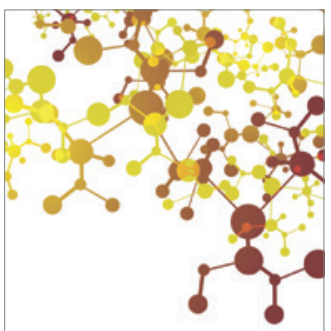

Journal of

Applied Chemistry

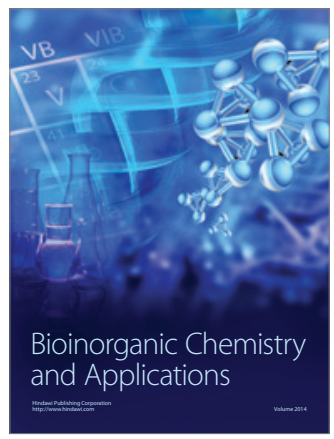

Inorganic Chemistry
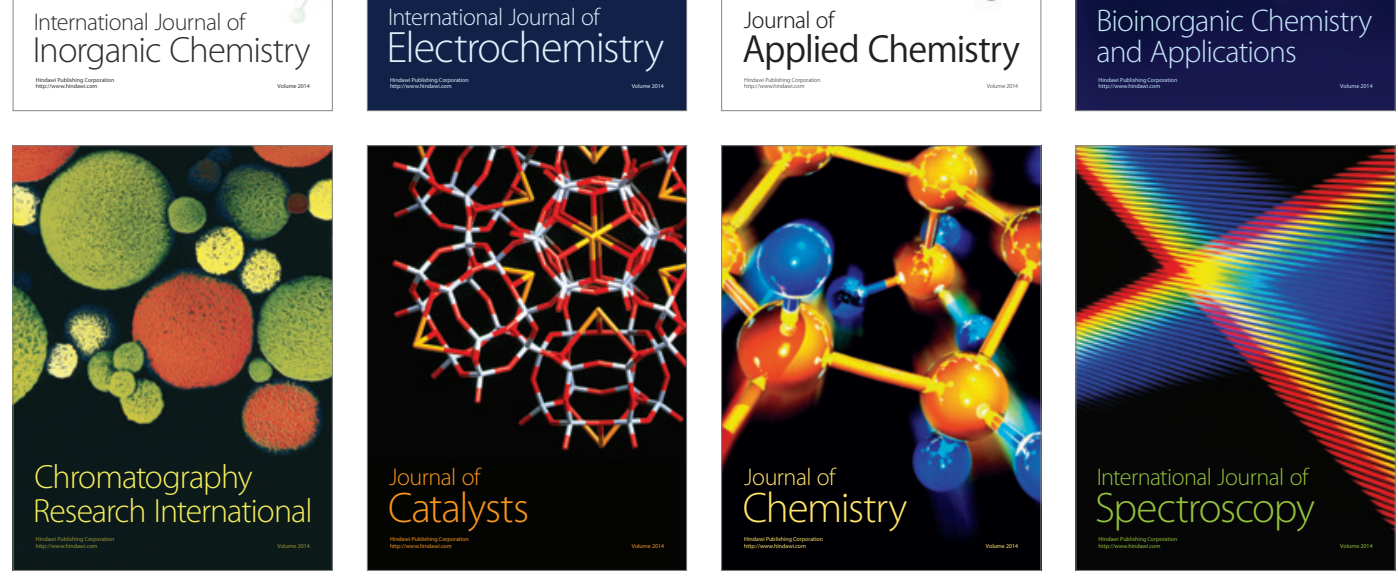